\title{
Os resultados de um laboratório de circuitos digitais remodelado para atividades práticas realizadas à distância, em tempo real, por imersão físico-virtual
}

DOI: 10.37702/2175-957X.COBENGE.2021.3565

Reginaldo Arakaki - reginaldo.arakaki@poli.usp.br

USP

RUA SOLDADO JOAO DE OLIVEIRA 369

05140-000 - SÃO PAULO - SP

Felipe Valencia de Almeida - felipe.valencia.almeida@usp.br

Universidade de São Pualo

Rua Marret 97

07095-140 - Guarulhos - SP

Victor Takashi Hayashi - victor.hayashi@usp.br

USP

Avenida Queiros Filho 277

09110-260 - Santo André - SP

Paulo Sergio Cugnasca - paulo.cugnasca@poli.usp.br USP

Av. Prof. Luciano Gualberto, travessa 3158

05508-010 - Sao Paulo - SP

Edson Toshimi Midorikawa - edson.midorikawa@poli.usp.br USP

Avenida Professor Luciano Gualberto, travessa 3158

05508-970 - São Paulo - SP

Resumo: Esse artigo descreve a transformação de uma disciplina de laboratório onde os alunos trabalham em pares para experimentação prática de circuitos digitais para o contexto da pandemia provocada pela COVID-19. O resultado foi a adoção de plataformas digitais que integraram os alunos às bancadas com resultados bastante positivos. Os indicadores coletados evidenciam os seguintes aspectos de aprendizado: a) organização de grupos de alunos, considerando o 
acesso remoto; b) os conceitos transformados em atividades experimentais, cujo desempenhos dos alunos são evidenciados por dados; c) as imersões dos alunos, cada um de sua casa, manipulando por meio de plataformas digitais os elementos de circuitos e os instrumentos de laboratório; d) o ciclo de projetos por duplas criando o clima de projetos independentes, com ritmo orquestrado pela equipe de professores, monitores e técnicos; e, por fim, e) a apresentação final dos projetos desenvolvido sobre os conceitos experimentados nas aulas iniciais. Dessa imersão, o grande destaque aparece no desenvolvimento das habilidades adicionais requeridas na formação profissional: comunicação, colaboração, planejamento, entregas, gestão de tempos e de complexidade e divulgação dos resultados.

Palavras-chave: Laboratório digital, integração físico-virtual, experimentação à distância, hard skills 


\section{Os resultados de um laboratório de circuitos digitais remodelado para atividades práticas realizadas à distância, em tempo real, por imersão físico-virtual}

\section{INTRODUÇÃO}

A equipe da disciplina PCS3635 de Laboratório Digital I da Escola Politécnica da Universidade de São Paulo sempre teve como referência uma boa aceitação por parte dos alunos, por alguns motivos: 1) A disciplina aplicada no terceiro ano é focada em circuitos digitais, com bancadas repletas de ferramentas e instrumentos e com atividades desafiadoras por serem de muitas manobras práticas, tanto nos circuitos como nos instrumentos de medição e de controle (LABDIG, 2021); 2) Os técnicos, professores e monitores conduzem um ambiente de estímulo ao aprendizado e de acolhimento de forma que muitos alunos, em intervalos entre aulas ou do almoço, se recolhiam neste ambiente, não somente para estudos, como também para compartilhar atividades, percepções e dificuldades de cursos por meio de um "diário de bordo"; 3) As avaliações em cada aula e o tipo de prova baseado em entregas de circuitos devidamente projetados e funcionando estabelecem a linha adequada para medir a assimilação do conhecimento de cada um dos alunos. Tudo isso sempre ocorreu na condição de todos os envolvidos juntos fisicamente, sem distanciamento social, como ilustrado na Figura 1(a).

Figura 1 - Laboratório com presença física (a), operado à distância (b) e o aluno numa sessão remota de entrega e demonstração de funcionamento do circuito digital ao professor (c).

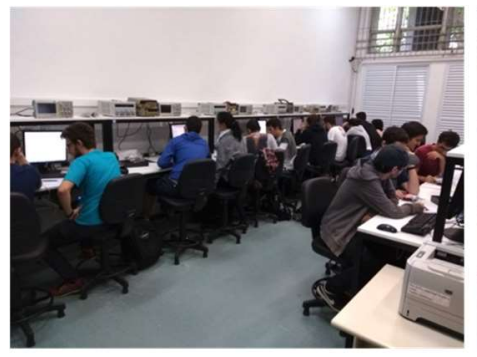

(a)

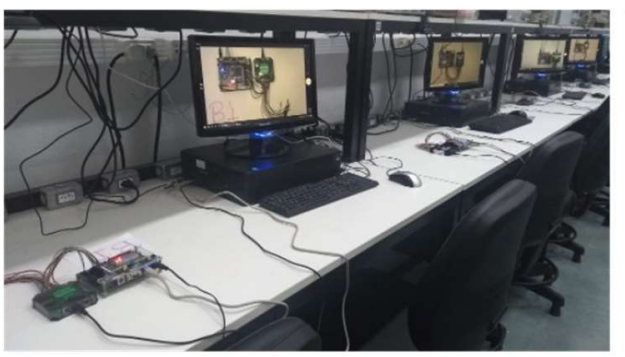

(b)

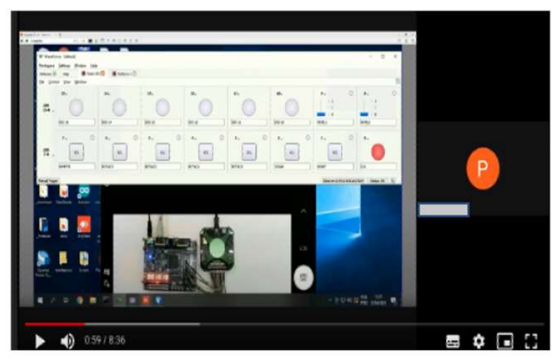

(c)

Fonte: Autoria própria

Porém, com a pandemia do Covid-19, as condições de trabalho mudaram. Os alunos, professores, monitores e técnicos da disciplina passaram a atuar separados fisicamente, e com um desafio muito difícil: Como conduzir a disciplina prática de laboratório à distância? Muitas iniciativas ficaram num cenário - possível no contexto - onde o professor criava vídeos de experimentos em laboratório no qual ele mesmo, com a ajuda dos técnicos, exemplificava na prática a montagem física, ilustrava o sucesso e os erros, fornecendo dicas de como proceder para os devidos testes e ajustes. Mesmo assim, do lado do aluno, tudo era um vídeo, ou seja, o laboratório se transformava em algo distante e o mais próximo da prática era captado virtualmente de forma passiva, com base em atividades realizadas por outras pessoas.

Nessa disciplina foram buscados alguns desafios e condições: 1) Juntar alunos, professores, monitores e técnicos usando uma plataforma digital como o Google Meet, Zoom ou outro; 2) Fazer a imersão dos envolvidos, no laboratório, para manipular à distância (diferente de ver um vídeo) a placa de elaboração de circuitos; nesta situação, o 
conceito de circuitos digitais por FPGA (Field-Programmable Gate Array) manipulável à distância funcionou; 3) Fazer acesso imersivo também nos equipamentos de energização e de medição digital pelo próprio aluno. A Figura 1(b) mostra as novas condições laboratoriais resultados do distanciamento social: o laboratório isolado e eventualmente com a presença de um técnico por vez para executar atividades de manutenção das bancadas; como resultado, a base da aula ocorria em sessões interativas, em tempo real, entre professores, alunos, monitores e técnicos, como ilustrado na Figura 1(c).

Este artigo descreve o planejamento didático sobre o ambiente imersivo remoto adotado na disciplina Laboratório Digital I. Descreve também os procedimentos aplicados para que os alunos pudessem desenvolver na prática os seus projetos e vivenciar os resultados práticos. O ciclo de engenharia, qual seja, o de conceber uma aplicação, projetar, implementar, testar e apresentar foi realizado com sucesso. Para isso, evidências foram coletadas e comentadas para um melhor entendimento da percepção dos alunos, da sua execução e dos resultados obtidos.

\section{LABORATÓRIO DE ELETRÔNICA DIGITAL E O APRENDIZADO}

A disciplina de Laboratório de Eletrônica Digital I foi renovada por uma série de aspectos, das quais se destacam duas. A primeira foi a pandemia da Covid-19, que impôs o distanciamento social, no qual alunos, professores, monitores e técnicos deveriam trabalhar em colaboração à distância, sem aglomeração física das pessoas. A segunda é decorrente da própria transformação digital, iniciada antes da pandemia - a desmaterialização de computadores e aparelhos smartphones e tablets que está em curso. Este contexto cria oportunidades em projetos de hardware com a mesma intensidade que em projetos de software. Isso se explica pelo seguinte: objetos conectados a sensores e atuadores, por processadores digitais, permitem interações por voz através de aparelhos como Alexa ${ }^{\mathrm{TM}}$, Google Assistant ${ }^{\mathrm{TM}}$, Siri ${ }^{\mathrm{TM}}$ e outros, ou seja, dispositivos digitais espalhados e integrados em aplicações como em cidades inteligentes, no corpo humano conectado, em carros conectados, no campo/agricultura conectada irão mudar a situação em que tudo está centrado nos smartphones com as centenas de milhares de Apps e SuperApps existentes.

A Tabela 1 mostra a estrutura de atividades da disciplina, separando um conjunto de experiências em 8 aulas, e as atividades de projeto em 5 aulas, além de provas práticas. 
28 a 30 de SETEMBRO

Tabela 1 - Planejamento da Disciplina em Atividades.

\begin{tabular}{|c|c|c|c|c|}
\hline Semana & $2^{\text {a feira }}$ & $4^{\text {a }}$ feira & Aula & Assunto \\
\hline 1 & $04 / 01$ & $06 / 01$ & Aula 1 & $\begin{array}{c}\text { Apresentações dos professores (1h30 a 1h45) } \\
\text { Experiência 1 }\end{array}$ \\
\hline 2 & $11 / 01$ & $13 / 01$ & Aula 2 & Experiência 2 \\
\hline 3 & $18 / 01$ & $20 / 01$ & Aula 3 & Experiência 3 \\
\hline-- & $25 / 01$ & $27 / 01$ & Aula 4 & OpenLab (27/01) => introdução ao Blynk \\
\hline 4 & $01 / 02$ & $03 / 02$ & Aula 5 & Experiência 4 \\
\hline 5 & $08 / 02$ & $10 / 02$ & Aula 6 & Experiência 6 \\
\hline-- & $15 / 02$ & $17 / 02$ & sem aula - (Carnaval) & Experiência 7 \\
\hline 6 & $22 / 02$ & $24 / 02$ & Aula 7 & P1 \\
\hline 7 & $01 / 03$ & $03 / 03$ & Aula 8 & Projeto - semana 1 \\
\hline 8 & $08 / 03$ & $10 / 03$ & Prova Prática & Projeto - semana 2 \\
\hline 9 & $15 / 03$ & $17 / 03$ & Projeto 1 & Projeto - semana 3 \\
\hline 10 & $22 / 03$ & $23 / 03$ & Projeto 2 & Feira Virtual \\
\hline 11 & $29 / 03$ & $31 / 03$ & Projeto 3 & Parte 2 \\
\hline 12 & $05 / 03$ & $07 / 03$ & Projeto 4 & Apresentação/reposição \\
\hline 13 & $12 / 03$ & $14 / 03$ & Demonstração dos projetos & \\
\hline 14 & $19 / 12$ & -- & Reposição da demonstração & \\
\hline
\end{tabular}

Fonte: Autoria própria

Do planejamento ilustrado na Tabela 1, podem-se elencar alguns destaques. Quais os fundamentos das aulas de experiências e qual a diferença das aulas de projetos? Nas aulas de experiências os alunos são orientados a experimentar elementos como contadores, memórias e circuitos de lógica de comparação e de contagem. E, como base para a integração destes circuitos básicos, a metodologia de projeto utilizada é a concepção de um sistema como uma combinação cuidadosamente projetada de um circuito de controle e um circuito de fluxo de dados. Ou seja, o aluno aprende a criar circuitos inteligentes baseados em máquinas de estados. A experimentação prática é estimulada em termos de ciclo de projeto. Para cada experiência, o aluno é desafiado a projetar um circuito combinando fluxo de dados com a máquina de estados. Tudo isso considerando o ciclo de engenharia, qual seja: 1) conceber as funcionalidades e identificar os requisitos não funcionais como lógicas de processamento, registros, entradas, saídas e frequência de operação; 2) projetar a solução; 3) implementar o conjunto de componentes; 4) simular o seu funcionamento baseado em planos de testes; e 5) promover o "deployment" do circuito na placa de FPGA. As etapas listadas de 1 a 4, o aluno no seu grupo (duplas) executa com os recursos de seus computadores pessoais para, em seguida, submeter no site da disciplina. No dia da aula experimental do laboratório, todo o material submetido é avaliado pelos professores e monitores. Com isso, os grupos fazem a experimentação prática, submetendo virtualmente o circuito à placa do laboratório e, com o apoio dos professores, monitores e técnicos, fazem o circuito funcionar, ajustando-o conforme os planos de testes.

Já as aulas de projetos ampliam a abrangência de aprendizado, com os alunos sendo desafiados a projetar novas funcionalidades de um Projeto-Base desenvolvido para atingir os objetivos de aprendizado das aulas de experiências. Neste caso, o projeto base utilizado foi um jogo de memória tomando como referência o brinquedo "Genius" (GENIUS, 2021). Nestas aulas de projeto, cada grupo avança por caminhos diferentes: eles devem pesquisar, estudar e criar funcionalidades, destacar os requisitos funcionais e não funcionais do projeto, criar a solução técnica e fazer todo o ciclo de projeto, dividindo a complexidade do circuito por entregas semanais, culminando com o projeto completo na aula denominada "Feira Virtual". Nessa Feira Virtual os alunos apresentam o sistema projetado para uma banca de professores da disciplina e outros convidados (professores e 
pesquisadores). As avaliações do desempenho e do aprendizado do aluno são baseadas nas entregas formalizadas em um Ambiente Virtual de Aprendizagem (AVA).

\section{O LABORATÓRIO E A IMERSÃO FÍSICO-VIRTUAL}

A imersão físico-virtual no laboratório foi possível mediante o estabelecimento de uma arquitetura didática, visando atender aos requisitos do ciclo de engenharia e viabilizar a participação ativa dos alunos na disciplina. A seguir serão descritas as aplicações que compõem esta arquitetura.

O AnyDesk é uma aplicação de desktop remoto, desenvolvido pela AnyDesk Software GmbH (ANYDESK, 2021). Seu propósito é disponibilizar uma interface de fácil uso e acesso, tornando menos custosa a comunicação remota a uma máquina, além de possuir suporte para diversos sistemas operacionais (Windows, Linux, macOS, Android, entre outros). Dentre suas possibilidades de uso, há licenças pagas e uma versão para uso gratuito, sendo que esta última se apresenta como adequada para o uso na disciplina Laboratório Digital I. Após a sua instalação, tanto na máquina de origem (alunos, monitores, professores) quanto na máquina de destino (laboratório), o usuário pode estabelecer a conexão com a máquina de destino por meio da permissão de um administrador ou então de uma senha de administrador. No contexto da disciplina, todas as bancadas do laboratório contavam com o AnyDesk instalado, e os professores, técnicos e monitores possuíam permissão de administrador para estabelecer a conexão remota dos alunos nas bancadas. Os alunos receberam uma tabela contendo os identificadores de cada bancada, sendo estes números de 9 dígitos que são interpretados pelo AnyDesk como o endereço lógico da bancada. Cada bancada também tinha uma câmera instalada, permitindo ao aluno visualizar o aparato experimental montado na bancada.

O Google Meet é um serviço da Google que recebeu grande destaque no ano passado por conta do aumento do uso de ferramentas voltadas para a criação de videoconferências (GOOGLE, 2021). Sua interface é simples, não sendo necessária nenhuma instalação para seu uso. Além disso, devido ao programa Google For Education, diversas instituições de ensino podem aproveitar de benefícios em seu uso, como por exemplo, uma maior duração máxima das videoconferências e um maior número de usuários simultâneos. No contexto da disciplina, foram criados três tipos de salas de videoconferência: a sala global, as salas das bancadas e a sala dos professores/monitores. A sala global é utilizada no primeiro momento da aula, onde os alunos se reúnem para realizar a atividade avaliativa inicial e assistirem à explicação síncrona dos professores sobre a experiência a ser realizada naquela aula. As salas das bancadas representam uma abstração virtual do espaço físico da bancada, onde cada grupo (dupla) estará alocado na sala correspondente à sua bancada física. A sala dos professores/monitores é utilizada para viabilizar uma comunicação rápida entre toda a equipe responsável pela disciplina. Caso algum problema seja identificado no decorrer da experiência, é possível alinhar uma postura com a equipe nesta sala e, em seguida, encaminhar diretrizes para todos os alunos na sala global.

A Figura 2 apresenta um diagrama simplificado do uso de cada uma das salas onde o 1 representa que cada aluno entra na sala correspondente a sua bancada e o $n$ indica que cada professor/monitor pode entrar em todas as salas das bancadas. 
Figura 2 - Diagrama do uso das salas de videoconferência

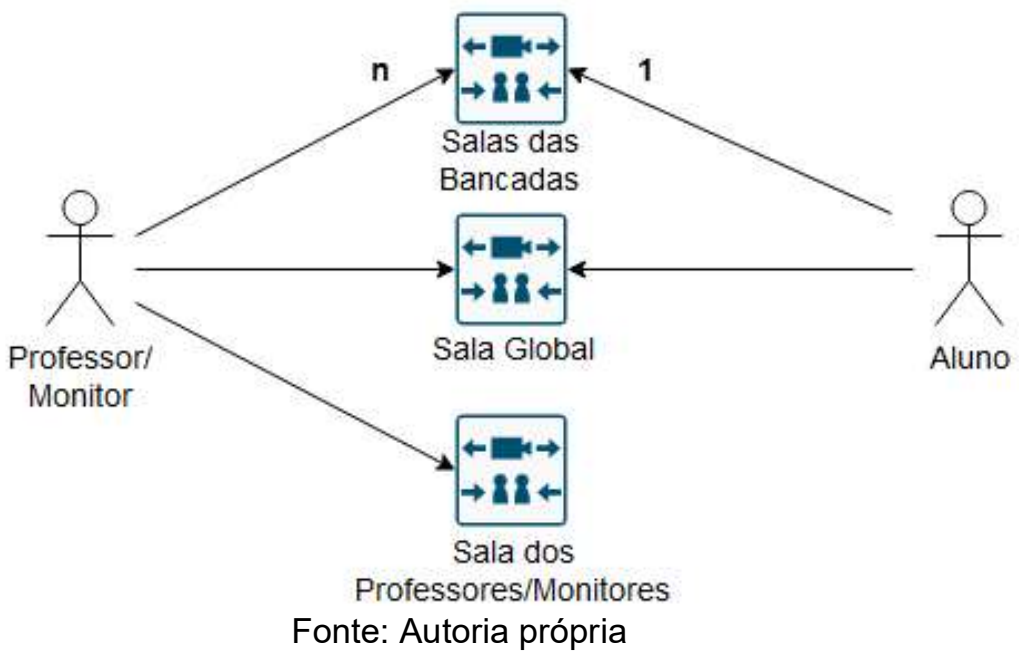

O Blynk é uma plataforma de Internet das Coisas (IoT) projetada com o propósito de facilitar projetos loT (BLYNK, 2021). Ele permite a comunicação entre diversos dispositivos utilizados em projetos da área, como por exemplo diferentes versões do Arduino, Raspberry Pi e microcontroladores ESP8266. Além disso, é possível realizar a integração destes dispositivos com uma interface mobile, disponível por meio do download do seu aplicativo para celulares na Google Play ou na App Store. Desta forma, o usuário pode interagir diretamente com os dispositivos conectados por meio de comandos em seu celular. Em um experimento de familiarização com loT, utilizou-se de placas Wemos D1 mini ESP8266 conectadas nas placas FPGA para que os alunos pudessem interagir com as placas FPGA por intermédio das placas Wemos conectadas na nuvem do Blynk. Cabe ressaltar que a opção de uso do Blynk foi uma escolha preliminar de projeto, sendo possível a adequação para uso de outras plataformas loT. Os alunos tiveram apenas uma familiarização com o Blynk, pois este não era o foco da disciplina de Laboratório Digital I. $\mathrm{Na}$ disciplina de Laboratório Digital II, que atua como continuação direta da disciplina descrita neste artigo, existe uma maior integração com dispositivos loT que podem estar localizados na residência do aluno. Neste caso, existe um uso mais intensivo do Blynk para viabilizar esta integração.

O LabEAD (HAYASHI, 2020a) é uma iniciativa feita em conjunto entre a Escola Politécnica da Universidade de São Paulo (Poli-USP) e a Universidade Federal do ABC (UFABC) com o propósito de disponibilizar uma infraestrutura de código aberto para viabilizar o ensino remoto de disciplinas de laboratório. Dando um enfoque nas disciplinas de laboratório de eletrônica digital, como a disciplina aqui apresentada, foi desenvolvida uma arquitetura que permite aos alunos interagir com as placas FPGA de maneira remota, fazendo com que a disciplina em questão não precise se limitar apenas ao uso de simulações. Os resultados preliminares foram apresentados em (HAYASHI, 2020b) e as percepções dos docentes e discentes relacionadas ao seu uso na disciplina foram apresentadas em (ALMEIDA, 2021).

Também deve-se destacar aqui dois softwares que são utilizados na disciplina tanto no oferecimento presencial quanto no remoto. São eles o Quartus Prime (INTEL, 2021) e o Waveforms (DIGILENT, 2021). O Quartus é um ambiente de desenvolvimento voltado para placas FPGA da Intel, já o Waveforms atua como uma interface e um driver para uso do instrumento Analog Discovery, utilizado nesta disciplina como osciloscópio e gerador de sinais de entrada do circuito. 


\section{RESULTADOS}

Com o objetivo de obter a percepção dos alunos sobre o oferecimento da disciplina, um questionário online foi aplicado na última semana do curso com a ferramenta Google Forms. Dos 48 alunos alocados a 4 turmas da disciplina Laboratório Digital I, 26 responderam ao questionário. O formulário consistiu das seguintes perguntas:

\section{Escopo Geral}

1. Como tem sido sua experiência com o ensino remoto? (pode selecionar mais de uma opção):
a. Aprendi a teoria de forma remota
b. Fiz simulações de forma remota
c. Fiz a parte prática de forma remota, em uma placa real
d. Não fiz nada de forma remota

2. Sobre as ferramentas de laboratório remoto (pode selecionar mais de uma opção):
a. As imersões por AnyDesk, Blynk e câmera são melhores que simulação
b. Prefiro simulações de experiências
c. Não entendi o uso da ferramenta
d. Não acrescentou nada

3. Sobre as atividades com Blynk (pode selecionar mais de uma opção):
a. Gostei da possibilidade de conectar casa e escola
b. Entendi o acesso remoto
c. Não entendi a plataforma loT
d. Não gostei

Sobre os projetos

4. Sobre o projeto dirigido realizado na segunda parte do curso (pode selecionar mais de uma opção):
a. Gostei do projeto
b. Prefiro aulas dirigidas
c. Não gostei do projeto
d. Aprendi a pensar um tema, definir requisitos e organizar soluções

5. Forneça o nome do seu projeto

6. Forneça o resumo do seu projeto (problema, valor/benefício agregado, resultados obtidos)

7. Sobre os itens abaixo, avalie seu grau de importância para o projeto (Necessário, Muito importante, Importância razoável, Pouco importante, Não faz diferença):
a. Apresentações "Elevator Pitch" no começo da aula
b. OpenLab
c. Experimentos anteriores (primeira parte do curso)

8. Sobre a colaboração remota com sua equipe, forneça uma nota de 1 a 5 (sendo 5 a melhor nota)

9. Se tivesse que fazer o projeto novamente, o que teria feito de diferente?

10. Descreva os principais aprendizados adquiridos com o projeto

Para cada pergunta, há um espaço para comentários com preenchimento opcional. As respostas da pergunta 1, ilustradas pela Figura 3, mostram que $80,8 \%$ dos alunos conseguiram realizar a parte prática com placas reais durante o ensino remoto, enquanto $88,5 \%$ fizeram simulações, e $92,3 \%$ aprenderam teoria de forma remota. 
Figura 3 - Considerações dos alunos sobre experiência com o ensino remoto

1. Como tem sido sua experiência com o ensino remoto? (pode selecionar mais de uma opção)

26 respostas

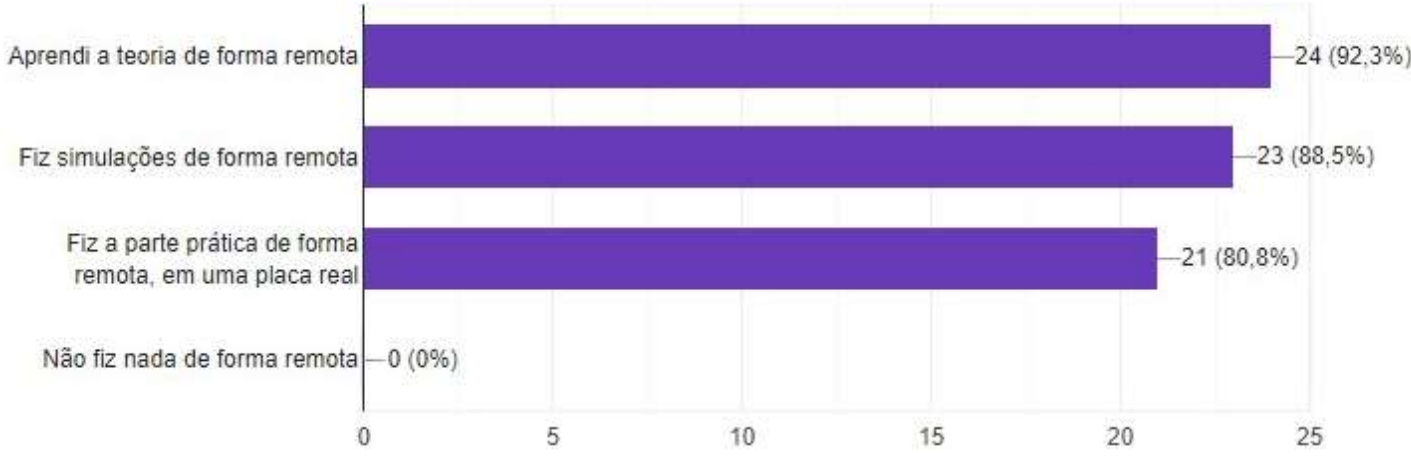

Fonte: Autoria própria

Cabem alguns destaques para comentários positivos dos alunos: "LabDig I foi sem dúvidas a disciplina que melhor se adaptou ao EaD. Conseguir usar a placa de casa foi ótimo para a matéria e não há reclamações quanto à adaptação, apenas elogios"; "A equipe está de parabéns. Como alunos, nós sentimos o esforço que foi feito para fazer da experiência a melhor possível".

Contudo, há uma preocupação com a carga horária despendida: "Acredito que o esforço de ambas as partes (professores e alunos) trouxeram boa adaptabilidade e efetividade ao ensino remoto. Entretanto, saliento a necessidade de uma melhor dosagem das tarefas passadas. O curso de Engenharia é corrido e puxado, entretanto, tenho a percepção que a quantidade de trabalho "extraclasse" aumentou demasiadamente. As disciplinas precisam conversarem melhor entre si. Esse é um problema antigo da Poli, mas em um momento de pandemia e ensino remoto, essa necessidade fica mais evidente, para que não haja sobrecarga de trabalho e prejuízo ao aprendizado."

Apenas $7,7 \%$ dos alunos preferem simulações de experiências, enquanto mais de 90\% concordam que "As imersões por AnyDesk, Blynk e câmera são melhores que simulação", e que "O acesso à placa FPGA, ao programa Waveforms e Blynk foram viabilizadas".

Um comentário merece destaque: "Achei a solução de acesso remoto genial. Acho que pode proporcionar para nós um insight de que podemos fazer muita coisa de forma remota, apesar da necessidade de colaboradores em algum local físico para configurar as placas e equipamentos".

Sobre o experimento com a plataforma loT e interação pelo celular, $80,8 \%$ dos participantes gostaram da possibilidade de conectar casa-escola, enquanto apenas 3,8\% afirmaram não ter gostado, conforme apresentado na Figura 4.

Dois comentários são destacados: "O uso do Blynk foi interessante, porém não acho que cabia nesta disciplina"; "Talvez um módulo (3 ou 4 aulas) dedicado apenas ao Blynk e IoT fosse mais interessante. O tópico é ótimo, mas achei um pouco fora do escopo do restante da matéria". 
Figura 4 - Considerações dos alunos sobre atividades com Blynk

3. Sobre as atividades com Blynk (pode selecionar mais de uma opção):

26 respostas

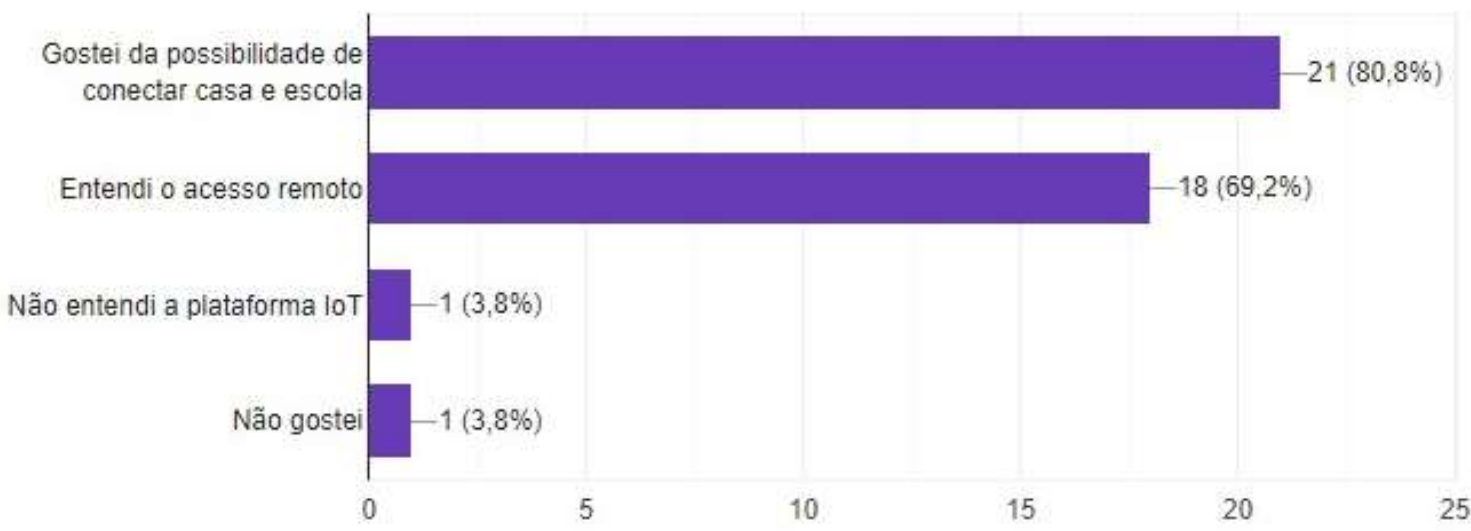

Fonte: Autoria própria

Quanto ao projeto, $80,8 \%$ dos alunos participantes afirmaram ter gostado do projeto, enquanto apenas $57,7 \%$ afirmaram ter aprendido a pensar um tema, definir requisitos e organizar soluções, conforme apresentado na Figura 5.

Figura 5 - Considerações dos alunos sobre o projeto dirigido

4. Sobre o projeto dirigido realizado na segunda parte do curso (pode selecionar mais de uma opção):

26 respostas

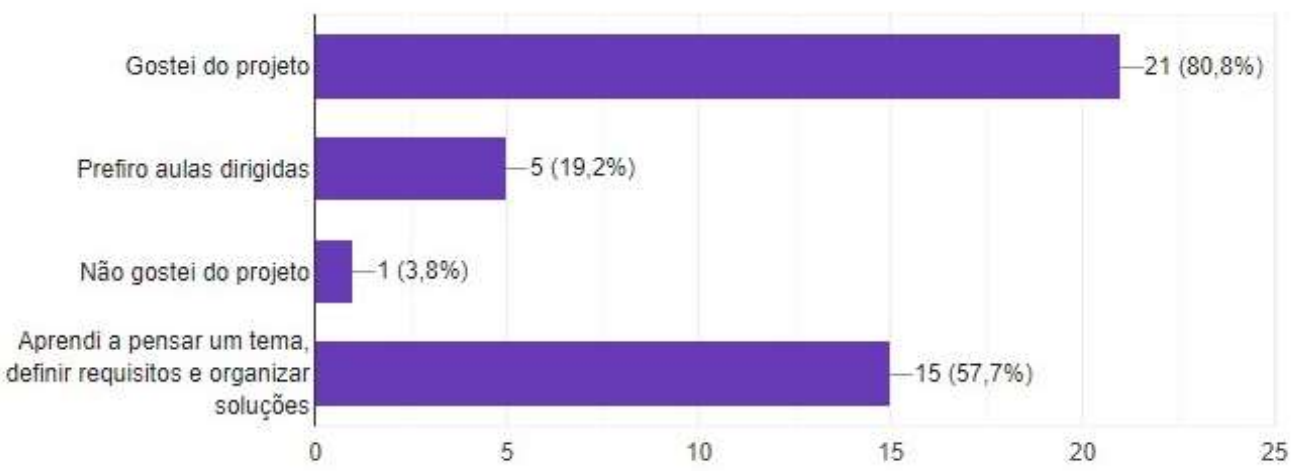

Fonte: Autoria própria

Dois comentários positivos merecem destaque: "Foi um projeto legal e a forma como a minha bancada resolveu (T1A1) foi interessante do ponto de vista de desenvolvimento de produto. Acredito que agregaria muito para a matéria ter um foco em questões de produto, como metodologia lean, MVP, etc."; "Achei ótimo, principalmente a progressão de independência que a matéria sugere. O modelo cabe perfeitamente nos interesses da disciplina e foi bem aplicado".

Os comentários negativos citam o tempo despendido e sobreposição com atividades de outras disciplinas. Seguem dois depoimentos dos alunos sobre os projetos:

"O contexto, embora fosse uma brincadeira, era criar uma extensão do jogo Genius para a aplicação de um teste de memória mais apurado (contexto de blitz). Acho que o valor agregado é percebido mais pela equipe, por conta da oportunidade de realizar um mini 
projeto de engenharia. Em termos práticos, o tema abordado e o produto final tem pouca relevância. Como resultado, foi possível cumprir com as especificações propostas, tendo um produto final compatível com o imaginado previamente".

"O objetivo de nosso projeto foi testar e treinar os reflexos do usuário, inspirado em exercícios realizados por pilotos de Fórmula 1. Como alunos, conseguimos utilizar as ideias ensinadas nas experiências de 1 a 7 aplicadas à uma ideia nossa, o que foi bem legal. Ficamos bastante satisfeitos com a versão final do projeto".

Conforme a Figura 6, os experimentos anteriores foram considerados como o fator de maior importância para o projeto. Em seguida está o OpenLab, correspondendo ao horário de laboratório agendado para uso livre dos alunos, fora do horário de aula, com apoio do técnico do laboratório.

Figura 6 - Grau de Importância dos Elementos para o Projeto

7. Sobre os itens abaixo, avalie seu grau de importância para o projeto:

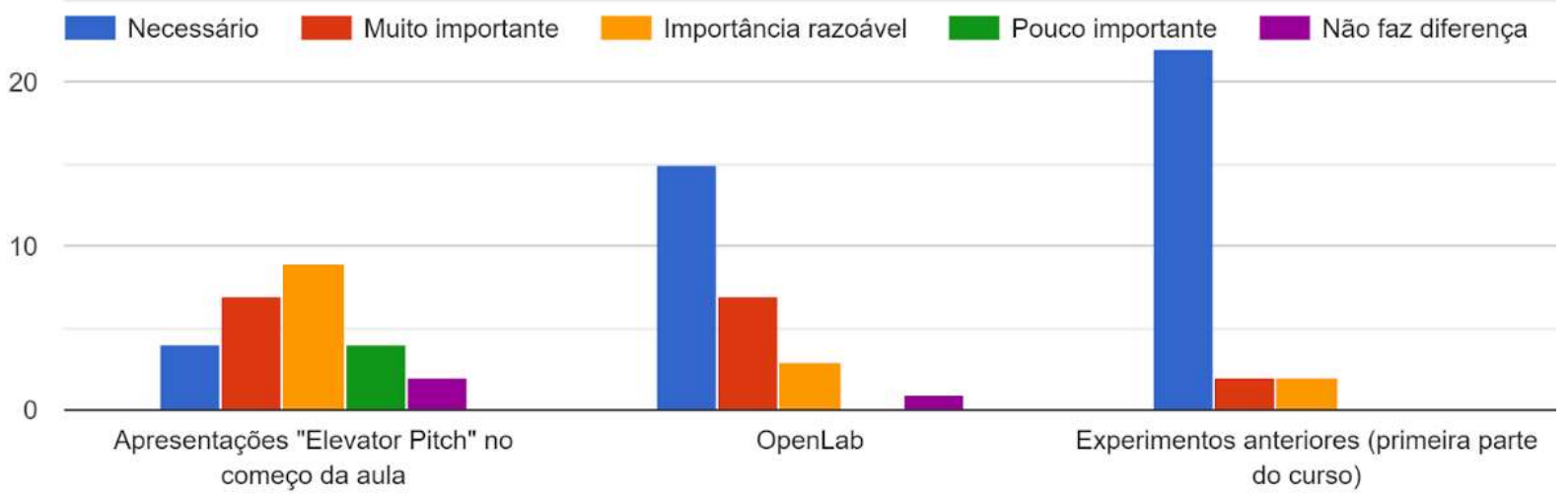

Fonte: Autoria própria

Conforme resultados da pergunta 8 do questionário, a colaboração remota foi avaliada com nota máxima por $61,5 \%$ dos alunos. Dois comentários destacam dificuldades encontradas: "Acredito que a comunicação em equipe foi muito boa, mas às vezes era difícil contribuirmos em conjunto em certas coisas, como arrumar os códigos VHDL"; "Acho que por ser remoto acaba se perdendo boa parte da qualidade da comunicação, especialmente considerando que a gente tem que descobrir qual o melhor jeito para colaborar".

Por fim, os principais aprendizados pela perspectiva dos alunos estão relacionados a aspectos técnicos e outras habilidades, como colaboração e gerenciamento de projetos de engenharia: "A aplicação dos conceitos teóricos vistos nas duas matérias de Sistemas Digitais (I e II) ministradas nos anos anteriores foi, definitivamente, o maior aprendizado das aulas do Laboratório Digital I, bem como o desenvolvimento do projeto. Além disso, o contato com ferramentas de análise do circuito, a introdução - ainda que simples - aos métodos de loT com o Blink e o desenvolvimento de um projeto de engenharia foram outros pontos muito interessantes durante a elaboração do jogo do Desafio da Memória e suas extensões. Finalmente, é possível afirmar que, mesmo com a situação da pandemia, a matéria teve uma elaboração que permitiu o aprendizado da modelagem de circuitos digitais de maneira completa e, sem dúvida, apresentou um dos melhores planejamentos das matérias ministradas não só durante o período de isolamento, mas também da Poli até o momento". 


\section{CONSIDERAÇÕES FINAIS}

Os resultados obtidos com o ensino remoto na disciplina Laboratório Digital I foram ótimos, segundo os desafios e planejamento estabelecido para a disciplina. Os objetivos de conceitos e habilidades em técnicas digitais foram atingidos. Os circuitos, com os seus elementos de controle e fluxo de dados foram utilizados e evidenciados por demonstrações práticas para bancas de avaliação, formada por professores da disciplina e professores e pesquisadores externos. Os destaques sobre essa dimensão foram os aspectos de engenharia exaltados durante o curso: técnicas de projeto sustentadas por mecanismos de simulação, testes e criação de pontos de acessos ("sondas") de sinais para depuração. $O$ aluno entendeu que um projeto teórico perfeito de pouco adianta se na prática não funciona. $\mathrm{E}$, geralmente, na primeira implementação, o circuito apresenta comportamento errado ou com imperfeições. Como identificar os erros e corrigir? Nesse contexto, a questão da importância do uso de metodologias de projeto foi amplamente avaliada, orientada e assimilada.

Conforme evidenciados no artigo, a disciplina PCS3635 Laboratório Digital I, implementada por imersão físico-virtual foi um sucesso na medida em que não somente reproduziu o ambiente de experimentação do laboratório, como ampliou as fronteiras de conhecimento dos alunos em termos de novas habilidades e capacidades, contribuindo para a sua formação profissional e acadêmica.

\section{Agradecimentos}

Agradecemos ao Departamento de Computação e Sistemas Digitais (PCS) da Escola Politécnica da USP pelo apoio e a todos os alunos e os técnicos que contribuíram para o sucesso no oferecimento desta disciplina.

\section{REFERÊNCIAS}

\section{Trabalhos em eventos}

ALMEIDA, Felipe; HAYASHI, Victor; ARAKAKI, Reginaldo; MIDORIKAWA, Edson; CUGNASCA, Paulo; CANOVAS, Sergio. Laboratório Digital à Distância: Percepções de Docentes e Discentes. In: I SIMPÓSIO BRASILEIRO DE EDUCAÇÃO EM COMPUTAÇÃO (EDUCOMP), 2021. Disponível em: https://sol.sbc.org.br/index.php/educomp/article/view/14499. Acesso em 27 abr. 2021

HAYASHI, Victor; ALMEIDA, Felipe; ARAKAKI, Reginaldo; TEIXEIRA, Julio Carlos; MARTINS, Danilo; MIDORIKAWA, Edson; CUGNASCA, Paulo; CANOVAS, Sergio. LabEAD: Laboratório Remoto para o Ensino de Engenharia. In: IX Workshops do Congresso Brasileiro de Informática na Educação (WCBIE), 2020. Disponível em: https://sol.sbc.org.br/index.php/wcbie/article/view/13044. Acesso em 27 abr. 2021

HAYASHI, Victor; ALMEIDA, Felipe; ARAKAKI, Reginaldo; MIDORIKAWA, Edson; CUGNASCA, Paulo; CANOVAS, Sergio. DESAFIOS E OPORTUNIDADES PARA O ENSINO REMOTO DA DISCIPLINA DE LABORATÓRIO DE ELETRÔNICA DIGITAL. In: XLVIII Congresso Brasileiro de Educação em Engenharia, 2020. Disponível em: http://abenge.org.br/sis submetidos.php?acao=abrir\&evento=COBENGE20\&codigo=COB ENGE20 00145 00003298.pdf. Acesso em 27 abr. 2021 


\section{Internet:}

ANYDESK. Software para computador remoto. Disponível em: https://anydesk.com/pt. Acesso em: 26 abr. 2021.

BLYNK. Blynk loT platform: for businesses and developers. Disponível em: https://blynk.io/. Acesso em: 26 abr. 2021.

DIGILENT. Waveforms. Disponível em: https://store.digilentinc.com/digilent-waveforms/. Acesso em: 05 mai. 2021

GENIUS. Jogo Genius. Disponível em: https://www.youtube.com/watch?v=VPK7XKIQQA8. Acesso em 05 de maio de 2021.

GOOGLE. Ferramenta de videoconferência Google Meet. Disponível em: https://meet.google.com/. Acesso em: 26 abr. 2021.

INTEL. Quartus Prime. Disponível em: https://www.intel.com.br/content/www/br/pt/software/programmable/quartusprime/download.html. Acesso em: 05 mai. 2021.

JUPITERWEB. Ementa da disciplina de Laboratório Digital I. Disponível em: https://uspdigital.usp.br/jupiterweb/obterDisciplina?nomdis=\&sgldis=PCS3635. Acesso em: 26 abr. 2021.

LABDIG. Página oficial da disciplina. Disponível em: http://www2.pcs.usp.br/ labdig/ Acesso em 05 mai. 2021.

\section{THE RESULTS OF A DIGITAL CIRCUIT LABORATORY REMODELED FOR PRACTICAL ACTIVITIES CARRIED OUT REMOTELY, IN REAL TIME, BY PHYSICAL-VIRTUAL IMMERSION}

Abstract: This article describes the transformation of a laboratory discipline where students work in pairs for practical experimentation of digital circuits in the context of the pandemic caused by COVID 19. The result was the adoption of digital platforms that integrated students into the workbench with results quite positive. The collected indicators show the following aspects of learning: a) organization of groups of students, considering remote access; $b$ ) concepts transformed into experimental activities, whose students' performances are evidenced by data; c) the students' immersions, each one from their home, manipulating circuit elements and laboratory instruments using digital platforms; d) the cycle of projects by pairs creating the climate of independent projects, with a pace orchestrated by the team of teachers, monitors and technicians; and finally e) the final presentation of the projects developed on the concepts experienced in the initial classes. From this immersion, the great highlight appears in the development of the additional skills required in professional training: communication, collaboration, planning, deliveries, time and complexity management and dissemination of results.

Keywords: digital laboratory, physical-virtual integration, distance experimentation, hard skills. 